\title{
CATIA-Based Urban Mini EV Design
}

\author{
Tian Pengfei*, Luo Yiping, Zhou Feng and Yuan Shu
}

Faculty of Automotive Engineering, Shanghai University of Engineering Science, Shanghai, 201600, P.R. China

\begin{abstract}
This article introduces a mini EV for urban single drive, a the car intended to work as conveyance for city workers, thereby relieving urban traffic pressure, improving traffic congestion and reducing urban pollution. The paper primarily designs a electric reversed tricycle and determines its motor and battery parameters, fixes the cockpit installation location by ergonomics, and finally completes vehicle arrangement. CATIA is mainly used for modeling and ergonomics analysis during the design process.
\end{abstract}

Keywords: CATIA, Ergonomics, Mini EV, Reversed tricycle.

\section{INTRODUCTION}

With the worsening of global energy shortage and environmental pollution, governments and the auto industry have clearly recognized that energy conservation is the main direction to the future development of automotive technology. Energy and environmental issues have become the biggest obstacle to the development of conventional cars, that is finding and developing new. Clean power source has become a hot research field in the today's automotive sector. EV has unparalleled advantages in terms of environmental protection and energy saving compared to conventional fuel vehicles because of its notable features of high efficiency, low noise and zero emissions [1]. Meanwhile, the development of modern high-tech, the birth of new materials and the wide used of electronics, motors and computer technology have greatly contributed to the renewal and development of electric vehicles technology [2]. Therefore, EV has potential to enter the mainstream transportation in $21^{\text {st }}$ century.

In addition, due to the rapid growth in the number of private cars, city traffic has become very busy and crowded. But when people drive to work, the vehicle's interior space has not been used effectively. That is if the car has the capacity to accomodate 4-5 people, there is only one driver sitting, resulting in vehicle flow increase instead of passenger flow increase. In order to alleviate this urban traffic congestion, electric bikes have become a popular means of transport. However, the electric bike has its inherent flaws such as its poor efficiency when coping with bad weather, poor security, etc. Therefore, we hope to design a product that can both have the advantages of cars and electric bikes, that is, a tiny, inexpensive, easy maintenance, secure, and energy-efficient electric car.

\section{WHOLE SCHEME DESIGN}

\subsection{General Design Requirements}

The mini EV designed in this paper is intended to achieve the electric drive, reduce vehicle weight, reduce drag and

\footnotetext{
*Address correspondence to this author at the Faculty of Automotive Engineering, Shanghai University of Engineering Science, Shanghai, 201600, P.R. China; Tel: 021-67791423; Fax: 021-67791423; E-mail: tianpf.2009@163.com
}

improve transmission under certain conditions (for a given performance requirement, the apparent size, etc.), so that endurance mileage is maximized. Here are some basic requirements for the vehicle design in Table 1.

Table 1. The basic requirements for $\mathrm{EV}$.

\begin{tabular}{|c|c|}
\hline Item & Parameter \\
\hline \hline Seats & 1 \\
\hline Vehicle quality $/ \mathrm{kg}$ & 240 \\
\hline Maximum mileage $/ \mathrm{km}$ & 75 \\
\hline Maximum speed $/ \mathrm{km} / \mathrm{h}$ & 40 \\
\hline Maximum gradeability & $\geq 15 \%$ \\
\hline Total length $/ \mathrm{mm}$ & $\leq 2200$ \\
\hline Total width $/ \mathrm{mm}$ & $\leq 1200$ \\
\hline Total height $/ \mathrm{mm}$ & $\leq 1500$ \\
\hline
\end{tabular}

\subsection{Traveling System}

\subsubsection{Wheels}

Cars generally have four wheels, but for mini EV, Tricycle style is considered the best choice whether it is its practical application or the ease of design and power steering. There are two main forms of tricycle arrangement, one front two rear and the other front one rear [3]. Tricycles with one front two rear have poor steering stability and can easily rollover when turning with fast speed, which greatly reduces the driving safety of mini EV. Tricycles with two front one rear are widely used in all kinds of energy-saving racing cars. This arrangement ensures that cars can obtain good handling stability and ride comfort even having small running resistance. What's more, tricycles with this arrangement don't need axle shaft, differential and some other structures, reduce the complexity of the mechanism and vehicle quality. And when the vehicle is decelerating before a curve, the load is assigned to two front wheels, so that cornering stability can easily be guaranteed. Therefore, the arrangement of two front one rear (two front steering wheels, one rear driving wheel) was selected for mini $\mathrm{EV}$. 


\subsubsection{Frame}

As an important part of mini EV, frame must have lower quality and sufficient strength and rigidity to ensure that it is not destroyed by stress and deformation. Generally, the quality of the frame itself should be controlled by the less than 10 percent of vehicle curbmass [4]. Considering the requirements of strength and rigidity of mini $\mathrm{EV}$, vehicle arrangement and ease of manufacture, Pipetype frame which is often used in energy-saving racing cars, is selected for mini EV. Pipe-type frame contains a lot of steel welded into a skeleton, then the various components are fixed on the frame [5]. The frame materials should cost lower while meeting the requirements of strength and stiffness. Aluminum alloy that has high specific strength and specific stiffness, low density and is cheap, should be the most appropriate material [6].

\subsubsection{Suspension}

For city driving, independent suspension often used to obtain a lower vehicle centroid height, better ride comfort and handling stability. Single wishbone, double wishbone, single trailing arm, double trailing arm, single oblique arm, McPherson and torsion bar, etc. are the most common types. Considering the wheels of two front one rear, rear-wheel drive and Pipe-type frame, double-wishbone independent suspension is used for front suspension, whereas single trailing arm independent suspension is used for rear suspension.

\subsection{Steering System}

The steering wheel is arranged according to the position of hands which is designed based on ergonomics. Steering shaft axis and steering wheel center are disposed within the vehicle longitudinal vertical plane. The position and tilt angle of steering wheel should make driver manipulate with portable devices [7]. In addition, the location of steering column should not hinder the driver's need of normal leg movement. Steering rod and steering gear are disposed between the upper and lower wishbones of double wishbone suspension and the front of frame, to check whether the interference will occur between the various components.

\subsection{Cockpit}

The cockpit is disposed in the back of the battery, in the rearward part of the EV, that is making steering system arrangement easy to handle. It can also increase the load applied on the rear axle, as well as the adhesion between the rear wheel and the ground.

\subsection{Battery}

Taking into account the use of rear-wheel drive, in order to increase the adhesion between the rear wheel and the ground and to shorten the distance between the battery and the motor, the battery is arranged in the back of the seat, before the top of the rear wheel.

\subsection{Cargo Box}

Cargo box is arranged above the rear wheel, making the car more compact layout.

\section{DRIVE SYSTEM PARAMETER CALCULATION}

\subsection{Motor Parameter Calculation}

The rated power and rated torque are the main parameters for motor. The rated power is determined by the maximum speed of EV to ensure the efficiency of the motor. Meanwhile, the power consumption of the vehicle increases with the speed of the vehicle, and the velocity of the vehicle in normal driving is generally lower than the maximum speed, so the rated power of the motor should be higher than or equal to all the running resistance power when the vehicle is running with the maximum speed [8].

The rated power of motor can be given by:

$P_{e} \geq \frac{1}{\eta}\left(\frac{m g f}{3600} u_{\max }+\frac{C_{D} A}{76140} u_{\max }^{3}\right)$

Where $m$ is the vehicle quality, $A$ is the frontal area, $\eta$ is the transmission efficiency, $f$ is the rolling resistance coefficient, $C_{D}$ is the air resistance coefficient, $u_{\max }$ is the maximum speed.

Rated torque can be calculated by the rated power and motor speed:

$T_{e}=\frac{9550 \cdot P_{e}}{n}$

When the vehicle is in the climbing conditions, the instantaneous power needs that overload power is higher than rated power, that can be given by:

$P_{\max } \geq \frac{1}{\eta}\left(\frac{m g f \cos \alpha}{3600} u_{a}+\frac{m g i}{3600} u_{a}+\frac{C_{D} A}{76140} u_{a}^{3}\right)$

Where $r$ is the tyre rolling radius, $i$ is the max slope, $\alpha$ is the max slope angle, $u_{a}$ is the climbing speed.

Also in the climbing conditions, the maximum toque of mini EV can be calculated by:

$$
T_{\max } \geq \frac{r}{\eta i_{0}}\left(m g f \cos \alpha+m g \sin \alpha+\frac{C_{D} A}{21.15} u_{a}^{2}\right)
$$

\subsection{Battery Pack Parameter Calculation}

\subsubsection{Battery Effective Capacity}

According to the design index of $75 \mathrm{~km}$ vehicle mileage, battery effective capacity can be given by:

$M_{e}=\frac{N}{V} \cdot \frac{\mathrm{S}}{u}$

Where $N$ is the motor rated power, $V$ is the motor rated voltage, $\mathrm{S}$ is the vehicle mileage, $u$ is the vehicle speed.

\subsubsection{Battery Rated Capacity}

At present, new power battery calibrate its rated capacity by $5 \mathrm{~h}$ discharge rate, and the above calculations show that the battery is actually working on $2 \mathrm{~h}$ discharge rate, However, Lead-acid battery discharge characteristics test data shows that: the effective capacity of the battery with $2 \mathrm{~h}$ discharge rate is only $70 \%$ of the rated capacity of the battery with $5 \mathrm{~h}$ discharge rate. 
The battery rated capacity can be written by:

$M=M_{e} / 0.7$

\subsection{Dynamic Parameter Calculation}

Depending on design specification, refer to the relevant information to draw basic parameters of mini EV in Table 2.

Table 2. Basic parameters.

\begin{tabular}{|c|c|}
\hline Item & Parameter \\
\hline \hline Vehicle quality/kg & 240 \\
\hline Maximum speed/km· h-1 & 40 \\
\hline Maximum gradeability/\% & 20 \\
\hline Rolling resistance coefficient & 0.01 \\
\hline Air resistance coefficient & 0.3 \\
\hline Frontal area/m2 & 2.1 \\
\hline Transmission efficiency & 0.98 \\
\hline Tire rolling radius $/ \mathrm{m}$ & 0.226 \\
\hline Vehicle mileage/km & 75 \\
\hline
\end{tabular}

According to the basic parameters above, drive system parameters are calculated by the basic dynamic equation of drive system. The results are shown in Table $\mathbf{3}$.

Table 3. Drive system parameters.

\begin{tabular}{|c|c|}
\hline Item & Parameter \\
\hline \hline Motor rated power/kw & 0.807 \\
\hline Battery pack rated output voltage/V & 48 \\
\hline Battery pack rated capacity/Ah & 55.71 \\
\hline
\end{tabular}

Taking care of both calculation results and actual situation, select $48 \mathrm{~V} / 1 \mathrm{kw}$ motor and select and four $12 \mathrm{~V} / 15 \mathrm{Ah}$ maintenance-free lead-acid motive battery are selected in series as the power source.

\section{COCKPIT DESIGN}

In this part, ergonomics will be used for aided design. First, establish a human model in Human Builder module in CATIA [9], then select the $95^{\text {th }}$ percentile of the human dimensions of Chinese adults and adjust the joint angle of human model as shown in Table 4.

There is an important point "H-point" that needs to be determined when arranging the position of human model's in body. H-point is the pivot point measured for the actual vehicle that connected human torso and thigh, $\mathrm{H}$-point is the reference point which can more accurately determine the location of the driver or the passenger in the seat [10].
Table 4. Joint angle of human model.

\begin{tabular}{|c|c|}
\hline Human Joint & Angle/( $\left.{ }^{\circ}\right)$ \\
\hline \hline neck joint & 165 \\
\hline Shoulder joint & 25 \\
\hline Elbow joint & 110 \\
\hline Hip joint & 105 \\
\hline Knee joint & 115 \\
\hline Foot joint & 100 \\
\hline
\end{tabular}

Firstly, draw a two-dimensional human model as described above, and determine the H-point according to the requirements of the cockpit arrangement. Then paint a slash that is 8 degrees to the vertical direction from H-point, and get point $\mathrm{F}$ at $765 \mathrm{~mm}$ upward along the slash from $\mathrm{H}$-point. Point $\mathrm{F}$ is equivalent to the highest point of the head of the $50^{\text {th }}$ percentile driver. Next, take point at $100 \sim 135 \mathrm{~mm}$ vertically upward from point $\mathrm{F}$, that point is the highest point of the roof trim lines. The roof above the roof trim lines includes steel sheet, skin and isolation layer, whose total thickness is about $15 \sim 25 \mathrm{~mm}$. Furthermore, the highest point on the cross-section of the car roof needs to add $20 \sim 40 \mathrm{~mm}$ from that point because the cap is generally upwardly convex contour surface and is symmetrical to the longitudinal plane of the car. As shown in Fig. (1).

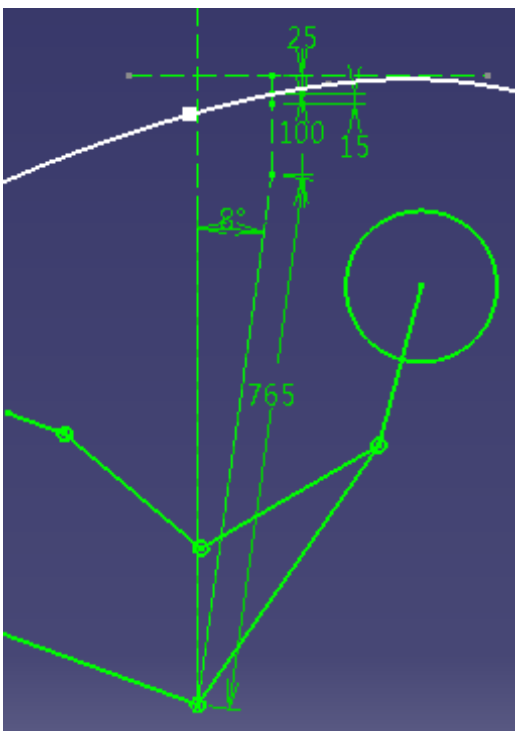

Fig. (1). The highest point of the roof contour.

The distance from H-point to the highest point of the roof is calculated as:

$h=765 \times \cos 8^{\circ}+100+15+25=898 \mathrm{~mm}$

Corresponding 2D drawings, a 3D model is drawn according to the related parameters determined by ergonomics as shown in Figs. $(\mathbf{2}, \mathbf{3})$.

\section{VEHICLE PARAMETERS}

The other relevant parameters of mini EV are calculated in the tables below according to design specification (Tables 5-7). 


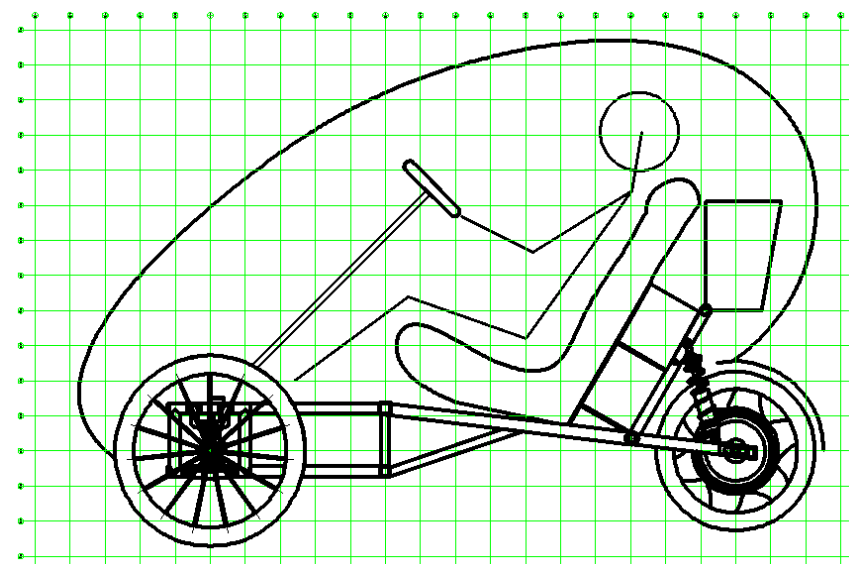

Fig. (2). 2D Drawings.

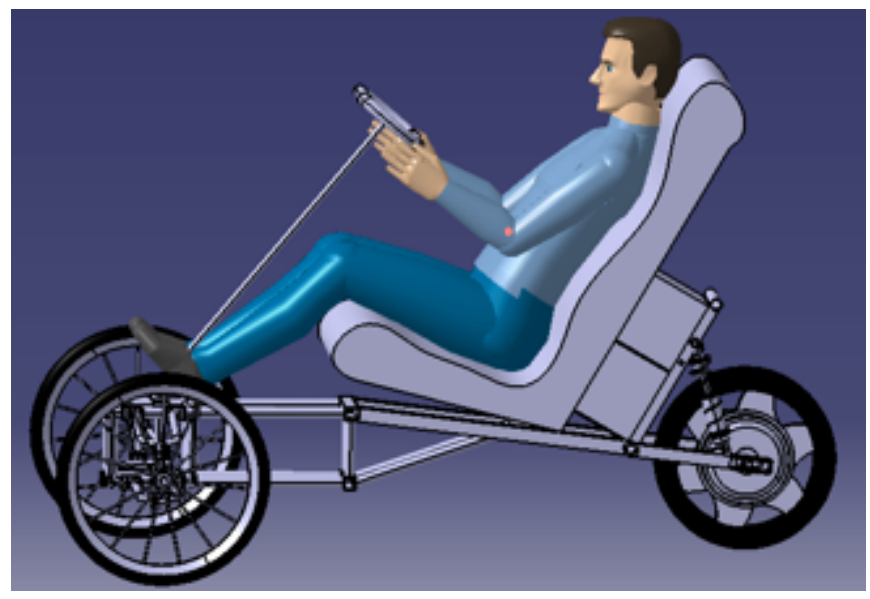

Fig. (3). 3D Model.

Table 5. Vehicle quality parameters.

\begin{tabular}{|c|c|}
\hline Item & Parameter \\
\hline \hline Curb mass/kg & 140 \\
\hline Total mass/kg & 240 \\
\hline Front axle load of car with full load/N & 768 \\
\hline Rear axle load of car with full load/N & 1632 \\
\hline Front axle load of car with no load/N & 814 \\
\hline Rear axle load of car with no load/N & 1386 \\
\hline
\end{tabular}

Table 6. Vehicle dimensions parameters.

\begin{tabular}{|c|c|}
\hline Item & Parameter \\
\hline \hline $\begin{array}{c}\text { Overall length } \times \text { Overall width } \times \\
\text { Overall height } /(\mathrm{mm} \times \mathrm{mm} \times \mathrm{mm})\end{array}$ & $2048 \times 1000 \times 1442$ \\
\hline Wheelbase $/ \mathrm{mm}$ & 1500 \\
\hline Front wheel tread $/ \mathrm{mm}$ & 900 \\
\hline Front overhang $/ \mathrm{mm}$ & 297 \\
\hline Rear overhang $/ \mathrm{mm}$ & 251 \\
\hline
\end{tabular}

Table 7. Trafficability parameters.

\begin{tabular}{|c|c|}
\hline Item & Parameter \\
\hline \hline Minimum ground clearance $/ \mathrm{m}$ & 0.18 \\
\hline Approach angle $/\left(^{\circ}\right)$ & 48.6 \\
\hline Departure angle $/\left(^{\circ}\right)$ & 65.3 \\
\hline Minimum turning radius $/ \mathrm{m}$ & 3.195 \\
\hline
\end{tabular}

\section{CONCLUSION}

1. This urban mini EV is only $240 \mathrm{~kg}$ in weight and has a small size. It is convenient to drive on the city roads, alleys, streets, communities, squares, parks, etc. It is also easy to park, easing the traffic pressure.

2. The mini EV is energy efficient, environmental friendly and low noise. And compared to the normal two wheels electric bicycles, mini EV is safer and stronger to adapt to harsh weather. It also meets people's normal demand of the car's dynamic performance by using high-performance hub motor and lead-acid battery.

3. The mini EV is cheap. It is expected that the market price will be less than $10,000 \mathrm{RMB}$. Also, it is expected to get good economic and social benefits after the car is put on the market.

\section{ABOUT THE AUTHORS}

First Author Tian Pengfei, Bachelor degree in engineering, Studying for Master Degree in Shanghai University of Engineering Science. The author's major is Vehicle Engineering.

Second Author Luo Yiping, University professor of Shanghai University of Engineering Science, Senior Engineer. The author's major is Automobile Manufacturing and Testing

Third Author Zhou Feng, Studying for Master Degree in Shanghai University of Engineering Science.

Fourth Author Yuan Shu, Studying for Master Degree in Shanghai University of Engineering Science.

\section{CONFLICT OF INTEREST}

The authors confirm that this article content has no conflict of interest.

\section{ACKNOWLEDGEMENTS}

This research was supported by An urban micro-electric car design (14KY0609).

\section{REFERENCES}

[1] F. Jiang, Z. Luo and L. Tong, "Status quo and development trend of electric vehicles," In: Energy Conservation and New Energy Vehicle Technology Forum, Wuhan, pp. 52-54, 2009.

[2] B. Men, Electric Vehicles, Xiangtan, 2010.

[3] Japan Solar Energy Society, Construction Principles, Design and Production of eco-Energy Electric Vehicle, Xi'an, 2010. 
[4] Z. Wang, "Structural performance simulation analysis and optimization of the frame of solar electric tricycle", M.S. thesis, Zhejiang University, Hangzhou, ON, China, 2006.

[5] R. Tian and G. Li, "Finite element model and the strength, stiffness analysis of the frame of a new sports tricycle," Tractor \& Farm Transporter, vol. 39, pp. 19-21, Apr. 2012.

[6] J. Zhou and G. Wang, "Selection and lightweight design of the frame of energy-saving vehicles," Auto Mobile Science \& Technology, vol. 5, pp. 41-44, Sep, 2008.
[7] X. Tang, "Vehicle Overall Design", Beijing, 2010, pp. 134-135.

[8] C. Liu, "Dynamic system parameter matching and dynamic performance simulation of pure electric vehicles," Channel Science, 2010.

[9] Y. Zhang, H. Hu and J. Qiao, "Advanced applications of CATIA V5 R20", Beijing, 2011.

[10] E. Mao, H. Zhang and Z. Song, "Vehicle ergonomics", Beijing: Beijing Institute of Technology press, 2007, pp. 17-18.

Received: January 8, 2015

Revised: January 15, 2015

Accepted: January 16, 2015

(C) Pengfei et al.; Licensee Bentham Open.

This is an open access article licensed under the terms of the Creative Commons Attribution Non-Commercial License (http://creativecommons.org/licenses/by-nc/4.0/) which permits unrestricted, non-commercial use, distribution and reproduction in any medium, provided the work is properly cited. 